\title{
Comparing an Approximate Queuing Approach with Simulation for the Solution of a Cross-Docking Problem
}

\author{
Roberta Briesemeister and Antônio G. N. Novaes \\ Department of Industrial Engineering, Federal University of Santa Catarina, 88040-900 Florianópolis, SC, Brazil \\ Correspondence should be addressed to Roberta Briesemeister; robries57@gmail.com
}

Received 24 February 2017; Revised 6 April 2017; Accepted 4 May 2017; Published 28 May 2017

Academic Editor: Ching-Jong Liao

Copyright (c) 2017 Roberta Briesemeister and Antônio G. N. Novaes. This is an open access article distributed under the Creative Commons Attribution License, which permits unrestricted use, distribution, and reproduction in any medium, provided the original work is properly cited.

\begin{abstract}
Cross-docking is a logistics management concept in which products are temporarily unloaded at intermediate facilities and loaded onto output trucks to be sent to their final destination. In this paper, we propose an approximate nonstationary queuing model to size the number of docks to receive the trucks, so that their unloading will be as short as possible at the receiving dock, thus making the cross-docking process more efficient. It is observed that the stochastic queuing process may not reach the steady equilibrium state. A type of modeling that does not depend on the stationary characteristics of the process developed is applied. In order to measure the efficiency, performance, and possible adjustments of the parameters of the algorithm, an alternative simulation model is proposed using the Arena ${ }^{\circledR}$ software. The simulation uses analytic tools to make the problem more detailed, which is not allowed in the theoretical model. The computational analysis compares the results of the simulated model with the ones obtained with the theoretical algorithm, considering the queue length and the average waiting time of the trucks. Based on the results obtained, the simulation represented very well the proposed problem and possible changes can be easily detected with small adjustments in the simulated model.
\end{abstract}

\section{Introduction}

The primary objective of any logistics system is to ensure high level of customer service, measured by product availability, on-time delivery, distribution in assortment and quantity requested, and, at the same time, using the least amount of company resources, whether in the form of costs and expenses or in the form of fixed assets and working capital. After all, we need to meet both customer needs for high level of service as that of shareholders who seek a return on invested capital (Van Belle et al. [1]).

The cross-docking technique offers a very important basic advantage: reducing or eliminating the need for product storage. The cross-docking is a distribution system in which the received goods in a Distribution Center is not stored as it has been traditionally performed in this sector but is labeled and then transferred to be loaded and distributed, being delivered to the customer immediately, or at least as soon as possible (Schaffer [2]).
Boysen and Fliedner [3] say that this logistics practice is mainly used in the execution of deliveries in urban centers, where the circulation of large vehicles is restricted in size and weight, preventing them from making deliveries. Such vehicles unload their products in a warehouse known as a cross-docking terminal. The products cross the warehouse on conveyor belts and/or in hand trolleys and then are loaded onto other vehicles, which will deliver them to their final destinations. If the goods are stored temporarily, it should be only for a short period of time. An exact limit is difficult to define, but usually less than 24 hours.

The incoming trucks go directly to a dock or wait in line until they are assigned to an unloading dock. As soon as the truck reaches the receiving dock, its cargo (e.g., pallets, containers, or boxes) is discharged and the final destination of the delivering truck is identified. The products are then transported to another internal door by some material handling device, such as a worker operating a cart or a conveyor belt system. There, the goods are loaded into an exit truck that will 
send them to the final destination, thus accomplishing the shipping order. Once an inlet truck is completely unloaded or an exit truck is fully loaded, the truck releases the dock to the entrance of another truck.

In order to have an effective cross-docking operation some requirements need to be met and this depends on the attention given to aspects such as partnership between company members, reliability in the supply scheme, effective communication within the organization and with the partners, qualified personnel (manpower), and strategic management.

According to Buijs et al. [4], three elements are recurrent in the cross-docking strategy: the basic operations, the objectives to be achieved, and the number of available docks, the latter being relevant because, in many cases, the terminal has to handle the unloading of several cargoes simultaneously, which allows for a shipping of goods more agile, and with the cargoes better consolidated.

In this context, logistic costs (storage costs, transport costs, and dispatch costs) are an important part of the current research. Part of the optimization in transportation costs involves a dock assignment problem, which includes dock assignment for the arriving trucks and also for the outbound trucks that load the finished products and deliver them to the final customers. A good programming of the docks, their dimensioning, and the definition of the external space of a Distribution Center assist the managers in the decision making regarding the unloading process, reducing the waiting time of the trucks in the queue, reducing costs, and offering a high service level to the end customer.

The cross-docking terminal analysis can be accomplished, on the one hand, with an appropriate mathematical queue model. Through it, one can analytically define probabilistic processes intended to quantify performance measures, expressing productivity/operability parameters and resulting costs. On the other hand, the cross-dock terminal analysis can be accomplished with a simulation model.

Van Belle et al. [1] and Agustina et al. [5] present an extensive review of the existing literature about crossdocking modeling. The discussed papers are classified based on the problem type that is tackled (ranging from more strategic or tactical, to more operational problems). None of these revisions focus specifically on the determination of the number of dock doors intended to minimize the queue size and the waiting times of the trucks that supply the crossdocking facility.

Thus, this study aims to contribute to the operational analysis of the cross-docking terminal framework, specifically focusing the inbound truck behavioral pattern, with two alternative analytical modeling approaches. With this, the objective is to keep the serving trucks staying as short as possible in the unloading dock. So, their terminal managers will have more agility in making decisions regarding dock utilization, with reduced costs, improved service levels, and ensuring end customer satisfaction. This study also contributes to the optimal sizing of the terminal unloading docks, determining the number of doors according to a previous modeling capacity analysis.

\section{Literature Review}

Cross-docking centers deal with different types of problems, such as the location and layout of the terminals (e.g., see Mousavi and Moghaddam [6]; Yang et al. [7]; Vis and Roodbergen [8]; Bartholdi III and Gue [9]), vehicle routing (see, e.g., Liao et al. [10], Gonzalez-Feliu [11], Dobrusky Fernando [12], and Lee et al. [13]), port allocation problem, and truck scheduling (see, e.g., Tsui and Chang [14]; Bartholdi III and Gue [15]; Soltani and Sadjadi [16]; Shakeri et al. [17]; Goddefroy and Alexandrer [18]; Konur and Golias [19]).

This study focuses on the problem of sizing the number of receiving doors to unload feeder trucks in a terminal that operates under the cross-docking concept. A vehicle that arrives at the cross-dock terminal to be unloaded and finds one or more unoccupied service positions is directed to one of them for immediate unloading. Often, however, all unloading positions are occupied and the vehicle must wait. For the dimensioning of the cargo receiving area in the respective dock it is necessary to determine the number of doors required for that and, concurrently, estimate the number of vehicles in the queue by adopting an adequate service level, in order to provide space for truck parking, and not keeping the vehicles waiting excessive time. The number of discharge positions operating in parallel at the receiving dock is determined by the application of a mathematical queuing model, or by simulation.

The complexity of cross-docking operations has been of great interest to researchers and practitioners in the areas of optimization, supply chain management, and operational research. The following are some published works related to the use of mathematical modeling and/or simulation for cross-docking terminals.

Based on research hypotheses that addressed crossdocking simulation problems, Rohrer [20] explained how the simulation helps to ensure the success of cross-docking operations. For example, the problem of allocating entrance and exit truck doors in a Distribution Center (DC) has been previously studied by simulation approaches.

Gue and Kang [21] introduce a new type of queue, called "staging queues," in the case of unitized loads, mainly on pallets, in order to compare different freight preparation protocols. The authors use the Arena Simulation package to investigate three areas.

Taylor and Noble [22] also use simulation to analyze staging methods in various cross-docking environments. In their study, three preparation alternatives and three output demand scenarios are analyzed. After the simulations, they evaluate those scenarios with four performance criteria. The issues raised by Taylor and Noble [22] motivated a study by Sandal [23] that analyzes the most appropriate preparation strategies in the cross-docking operation according to the attributes of the load of trailers, in order to allow an optimized load on the trucks. Integrated to the algorithm developed in this mentioned study, a simulation model using the Arena Simulator analyzed four preparation strategies in a crossdock environment was developed and applied.

Chen et al. [24] study a similar problem which they call the multiple cross-dock problems. The major differences 
observed were that supplies and demands are not separable and that different products can be considered together (multicommodity flow problem). Also, transportation times in this approach are not taken into account. An integer programming formulation of the problem is provided, together with a proof of its NP-completeness. The authors proposed three heuristics (simulated annealing, tabu search, and a combination of both) to solve the problem. These heuristics provide better solutions than those obtained by solving the integer programming formulation with CPLEX, within only less than $10 \%$ of the time used by CPLEX. Among the three heuristics, tabu search seems to give the best results.

Arnaout et al. [25] propose a simulation model of discrete events of cross-docking operations, revealing some of the most important parameters that should be investigated. The proposed model was generated with the aid of the Arena Simulator and uses discrete events to randomly allocate orders in three different warehouses. The stochastic nature of the system allowed us to analyze different scenarios and to reveal the importance of some model parameters.

Some papers cited here show the importance that the simulation tool has been of, both in academic and business environments, especially for applications in manufacturing systems, handling, and materials storage, especially in the aid to the use of the logistics technique involving crossdocking. However, there is a gap in the literature regarding the optimization process to determine the number of receiving doors on a DC.

\section{Problem Statement}

Among many difficulties found in the construction of complex simulation models, the modeling of nonstationary stochastic processes is certainly a case. Without even entering the mathematical formalism of the definition of these applications, consider, as an example of this type of process, a call center to the public where the calls occur randomly, but with different rates of arrivals by 30-minute intervals. This randomness is simulated in software by generating random numbers in compliance with a determined probability distribution (Poisson, Exponential, normal, Weibull, etc.). The amount of calls generated in the model, for the period, should converge on average to the value defined by the arrival rate. Bear in mind, however, that this should occur despite the intrinsic randomness to the occurrences of these calls, questions, complaints, and so forth (Ferreira [26]).

In the Distribution Center that operates cross-docking logistics situations, this disposal is absolutely unacceptable or impractical. Therefore, the administrator must make a schedule of receiving goods, so that the space available for their (temporary) storage is not completely filled and the amount of unloading doors is in accordance with the quantity of products received per day, since this would generate long queues in its surroundings until all the discharge could be performed, raising costs and compromising the entire logistics operation.

Thus, the arrival of goods in the Distribution Center is done through an adequate logistics programming conducted

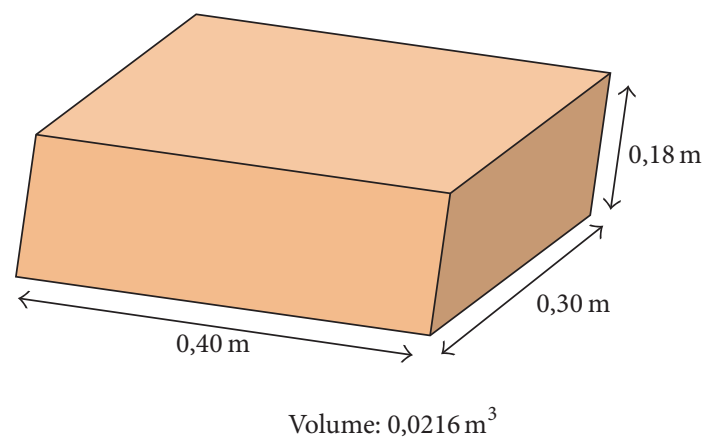

FIGURE 1: Standard packaging box for products.

by managers, but it still depends on how well this loading center has been designed, specifically to determine the number of doors (Schwind Gene [27]).

This study proposes an approximate theoretical mathematical queuing model to be applied to the problem of door allocation, considering the queues to be nonstationary. This theoretical model will be later confronted with a simulation model, using the Arena software, in order to validate the former. The advantage of using simulation is that it can replicate activities and congestion in a cross-dock, as well as providing accurate information that enables correct decision making to improve cross-docking performance.

It is not the object of this work to deal with the internal part of the cross-dock operations with elements such as allocation of material handling equipment and labor effort analysis, to assist in the unloading/loading of the trucks, as well as the displacement of the materials inside the terminal. To this respect, the minimization of the internal transfer distance of goods from the receiving doors to the shipping ones, which is subject of study by some authors, is not part either of the objectives of this work.

3.1. Application Example. A supermarket chain that operates a cross-docking terminal receives products from supplier companies and transfers them to vehicles that supply the company's stores. It is assumed, in a preliminary approximation, that all products arrive in uniform cartons, with the dimensions shown in Figure 1. The carton shown in Figure 1 is understood as the equivalent handling unit of product. Thus, the flows of products that arrive, are handled, and are subsequently shipped in the terminal are measured in a simplified number of equivalent boxes.

The terminal continuously receives an average of 10,625 equivalent cartons per hour. The composition of the feeder truck fleet is shown in Table 1.

\section{Theoretical Model of the Nonstationary Queue}

Figure 2 shows the arrival process of supply trucks at the terminal for a scheduled cross-docking operation, where operators are required to send their inbound vehicles respecting a predefined time window (diagram of Figure 2 is based on Odoni and de Neufville's [28] article). It is observed that, in 
TABLE 1: Composition of the fleet of feeding vehicles.

\begin{tabular}{|c|c|c|c|c|}
\hline Type of truck & $\begin{array}{c}\text { Charge } \\
\text { capacity }(\mathrm{kg})\end{array}$ & $\begin{array}{c}\text { Arrival } \\
\text { frequency } \\
(\%)\end{array}$ & $\begin{array}{l}\text { Number of } \\
\text { cartons per } \\
\text { truck }(\mathrm{u})\end{array}$ & $\begin{array}{c}\text { Average } \\
\text { discharge } \\
\text { time per } \\
\text { vehicle (min) }\end{array}$ \\
\hline Toco & 6.000 & 70 & 428 & 40 \\
\hline Truck & 10.000 & 20 & 714 & 67 \\
\hline $\mathrm{VUC}^{(*)}$ & 3.000 & 10 & 214 & 24 \\
\hline $\begin{array}{l}\text { Average } \\
\text { situation }\end{array}$ & 6.300 & & 463,8 & 43,8 \\
\hline
\end{tabular}

${ }^{(*)}$ City utilitarian vehicle.

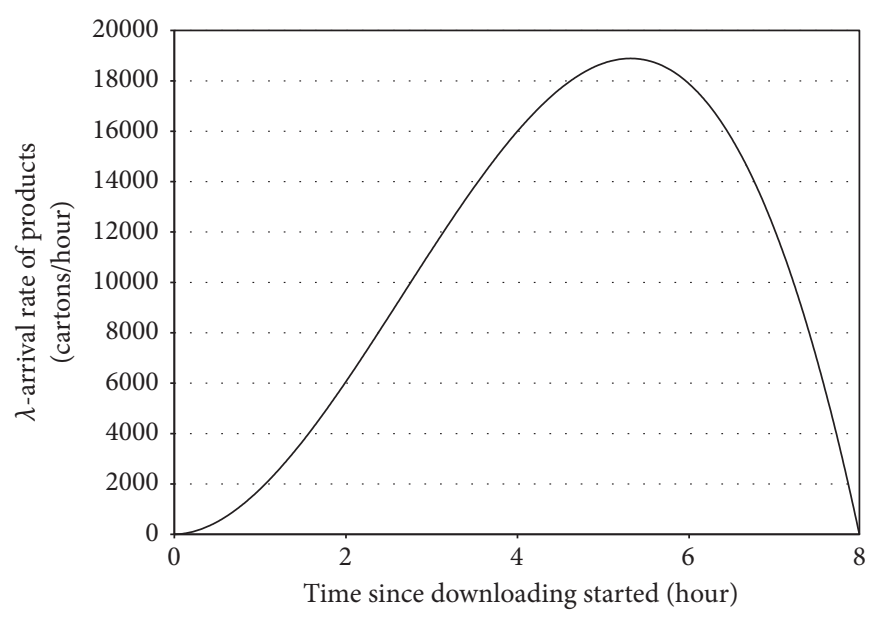

FIgURE 2: Arrival rate of the incoming feeder trucks at the cross-docking terminal, fitted with the third-degree mathematical curve (1).

situations of this type, with sufficiently strict operating rules, the stochastic queuing process may not reach the steadystate equilibrium mentioned above for the classical queuing models. It is then necessary to apply a type of modeling that does not depend on the stationary characteristics of the process. Newell $[29,30]$ has developed a rather unique and robust modeling solution for queuing problems with transient and nonstationary states. For this purpose, a continuous representation is used, in which the arrival process is represented as if its elements were a fluid in movement.

It is considered a hypothetical case of a supermarket chain (real data is firm proprietary) that owns a cross-docking terminal, which operates the unloading of supply vehicles during a time window of $T=8$ hours per day, with a total of $G$ $=85,000$ cartons per day. In the application, each vehicle has, on average, 463.8 boxes. The integral of $\lambda(t)$ in the interval $0 \leq t \leq T$ should equal the total demand observed in the time window, obtaining the final expression:

$$
\begin{array}{r}
\lambda(t)=\left(\frac{12 G}{\tau^{4}}\right)\left[(T-t)^{3}-2 T(T-t)^{2}+T^{2}(T-t)\right], \\
(0 \leq t \leq T) .
\end{array}
$$

4.1. Queue Forming Process. Let $D(t)$ be the cumulative function of the unloading capacity of the $n$ receiving doors which operate simultaneously and in parallel at the terminal dock. Each door has the capacity to download, on average, $\mu$ boxes per hour. The total capacity average of the discharge doors is therefore equal to $\mu n$. It has been assumed that the average discharge capacity is constant over time; that is, $D(t)$ varies linearly as a function of time:

$$
D(t)=a+\mu n t .
$$

It was assumed that there is no queue at time $t=0$, that is, $Q(0)=0$, where $Q(t)$ expresses the queue size at time $t$. This no-queue situation tends to remain for some time $t_{0}$, when $\lambda(t)$ reaches a growth rate equal to $\mu n$ (Rohrer [20]) and where the curve $A(t)=\int_{0}^{t} \lambda(t)$ separates from the line $D(t)$, as shown in Figure 3.

It is therefore necessary to determine $t_{0}$ such that

$$
\lambda\left(t_{0}\right)=\mu n \text {. }
$$

That is, the instant $t_{0}$ is one in which the arrival rate of the products becomes equal to the total discharge capacity of the dock (Newell [30]), including all the doors; that is,

$$
\left(\frac{12 G}{T^{4}}\right)\left[\left(T-t_{0}\right)^{3}-2 T\left(T-t_{0}\right)^{2}+T^{2}\left(T-t_{0}\right)\right]=\mu n .
$$

In this application, the instant $t_{0}$ is determined by minimizing $f(t)$ given by the absolute value of the difference $\lambda(t)$ and $\mu n$, according to relation (3)

$$
f(t)=\min \{\operatorname{abs}[\lambda(t)-\mu n]\} \rightarrow t_{0},
$$




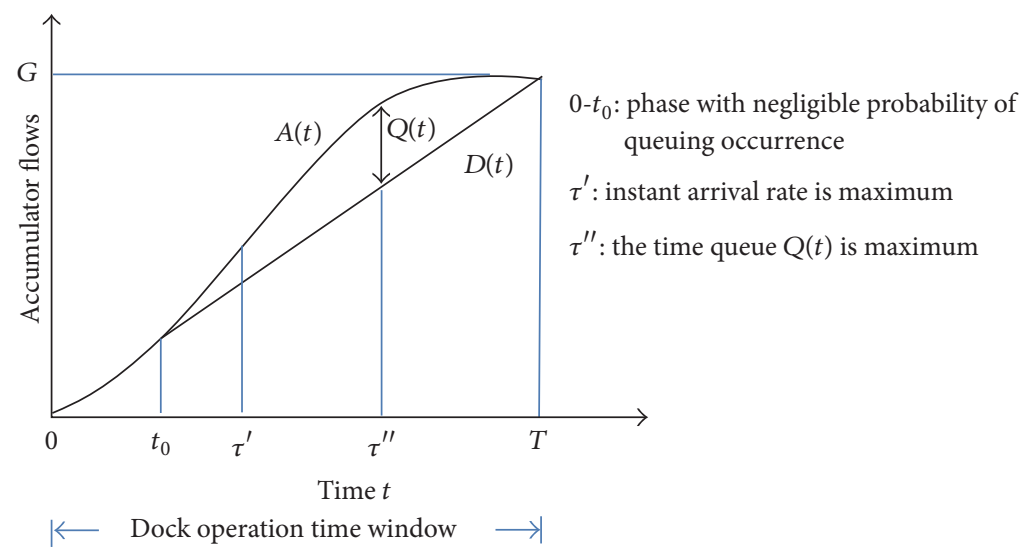

FIGURE 3: Phase between instant zero and instant $t_{0}$, when there is practically no queue.

and applying a golden search numerical method (Novaes Antônio [31]) to solve (5).

In Figure 3 it is noted that $D\left(t_{0}\right)=A\left(t_{0}\right)$, since both are coincident in that position. Thus, the equation of the line $D(t)$ (2) can be expressed specifically for $t=t_{0}$ :

$$
\begin{aligned}
A\left(t_{0}\right) & =a+\mu n t_{0}, \\
D(t) & =A\left(t_{0}\right)-\mu n t_{0}+\mu n t .
\end{aligned}
$$

Figure 3 shows that the supply vehicle service process ends at time $t=T$, when the last truck starts to be unloaded. But in most cases this is not what actually happens. In fact, $t_{\mathrm{Q}}$ is the point at which $D(t)$ equals the value of $G$, that is, the moment when the service supply $D(t)$ fully satisfies the daily demand $G$. Then the value of $t_{\mathrm{Q}}$ is calculated through of the expression (7), making $D(t)=G$ :

$$
t_{\mathrm{Q}}=\frac{\left[G-A\left(t_{0}\right)+\mu n t_{0}\right]}{\mu n} .
$$

4.2. Queue Extension. Theoretically, it can be considered that, for nonstationary queuing situations of this type, terminal operation could be performed with any value of $n$ equal or greater than unity. The correct action to take is to establish a maximum daily operation time of the dock and to size the number of unloading doors, so that the daily operation time of the terminal does not exceed a certain limit.

The extension $t$ of the queuing process varies between instants $t_{0}$ and $t_{Q}$; for $0 \leq t \leq t_{0}$, the queue is null. We have the following formulations:

(a) $0 \leq t \leq t_{0}$,

$$
Q(t)=0
$$

(b) $t_{o} \leq t \leq T$,

$$
Q(t)=A(t)-D(t) .
$$

(c) $T<t \leq t_{\mathrm{Q}}$,

$$
Q(t)=G-D(t) .
$$

Three parameters are of interest to the analysis: the average queue, considering all the time of discharging operation, the average queue considering only the congestion phase, and the maximum value of the queue in the three above cases.

4.3. Queue Time. The article by Little and Graves [32] shows the validity of

$$
Q=\lambda * W,
$$

where $Q$ is the average number of elements in the queue, $W$ is the average waiting time of an element in the queue, and $\lambda$ is the average arrival rate per unit time. Expression (12), widely used in practice, was given the name "little law" because of its almost universal character.

Expression (12) is used in this work to estimate the average waiting time in the queue, given by $W=Q / \lambda$.

4.4. Random Variation of Queue Extension. If we divide the time window $0 \leq t \leq T$ into infinitesimal intervals $d t$, in each of them the arrivals can be considered as obeying a Poisson distribution, with mean $\lambda(t)$ (Newell $[29,30]$ ). Because it is a Poisson distribution, the variance is equal to average $\lambda(t)$. On the other hand, the discharge time of a vehicle is governed by a log-normal distribution in our application. The attendance rate is running at a rate equal to $n \mu$, with variance equal to $C V \times n \mu$.

The variance of the difference between the arrival process and the service process is $(A[t])$ and the discharge of the trucks $(D[t])$, accumulating at time $t$. Thus, the queue variance, which is cumulatively generated over time, is given by (Newell [30])

$$
\operatorname{var} Q(t) \cong t[\lambda(t)+C V * n \mu],
$$

with the standard deviation

$$
\sigma_{\mathrm{Q}}(t)=\{t[\lambda(t)+C V * n \mu]\}^{1 / 2} .
$$

A computer program written in Delphi/Pascal, Berlin Version 10.1, by Embarcadero Technology, Inc., was developed to determine the main queue elements indicated in this 
section. The decision variable of the problem is $n$, the number of discharging doors at the cross-docking terminal, varying in the interval $10 \leq n \leq 29$.

4.5. Distribution of Vehicle Discharge Time. It was assumed that discharge times are governed by log-normal distribution, with mean $\bar{S}=43,8 \mathrm{~min}$ and standard deviation $\sigma_{S}=12,8 \mathrm{~min}$. The probability density function $f(S)$ is given by

$$
f(S)=\frac{1}{S v \sqrt{2 \pi}} \exp \left[\frac{-(\ln S-m)^{2}}{2 v^{2}}\right],
$$

where $m$ and $v$ are two auxiliary parameters given by

$$
\begin{aligned}
& m=\ln \left(\frac{\bar{S}^{2}}{\sqrt{\sigma_{S}+\bar{S}^{2}}}\right), \\
& v=\sqrt{\ln \left(\frac{\sigma_{S}}{S^{2}}+1\right)} .
\end{aligned}
$$

The discharge rate at any door of the receiving dock is the inverse of the discharge time

$$
\bar{\mu}=\frac{u * 60}{\bar{S}} .
$$

With $\bar{S}$ expressed in minutes and $\bar{\mu}$ expressed in boxes unloaded per hour and where $u$ is the average load of a truck (cartons), we obtain $\bar{\mu}=635.3$ boxes discharged per hour.

4.6. Average Occupation of the Unloading Dock. The time the receiving dock is effectively in use when unloading vehicles is

$$
D H=n \times \tau,
$$

where $\tau$ is the daily use time of the dock (hours).

The time $\tau$ is equal to $t_{Q}$ plus the mean discharge time $\bar{S}$; that is,

$$
\tau=t_{\mathrm{Q}}+\bar{S} .
$$

In (19), the term $\bar{S}$ refers to the additional time which is related to the trucks that arrive at the terminal at the last allowed moment.

4.7. Average Time of Stay in the System. Let $\gamma$ be the fraction of the arriving vehicles that do not enter the queue. On the other hand, $\overline{W T}_{\text {fila }}$ is the average time in the queue, calculated within the time interval when congestion (i.e., queue) occurs. When queuing occurs, the average time in the system is equal to the sum of the time in the queue and the unloading time. Conversely, when there is no queue, the time in the system is equal to the unloading time. Thus, the average time in the system, $\overline{W T}_{\text {syst }}$, is given by

$$
\overline{W T}_{\text {syst }}=(1-\gamma)\left(\overline{W T}_{\text {fila }}+\bar{S}\right)+\gamma \bar{S} .
$$

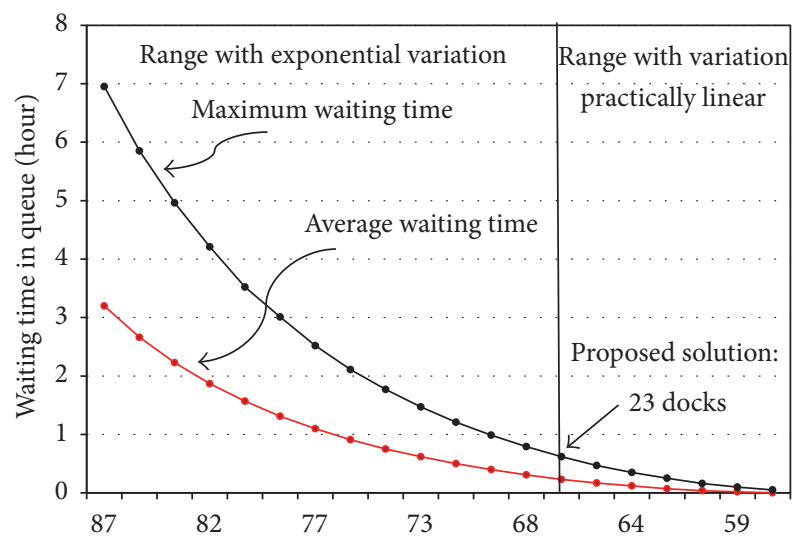

FIGURE 4: Queue waiting time based on dock utilization rate (\%).

4.8. Number of Receiving Doors in the Analysis. To determine the upper end of $n$, which was called $n_{Q}$ in the program developed in Pascal, it is worth stressing that the line $D(t)$ does cross the curve $A(t)$ for $t_{0} \geq(2 / 3) T$. In such a condition, the line representing $D(t)$ is tangential to the curve $A(t)$. From that point on, it becomes uneconomic to add more discharging doors to the dock, since the benefit would be nil.

On the other hand, for small values of $n$, the value of $t_{\mathrm{Q}}$ might increase too much, above acceptable operating conditions. With these aspects in mind, the following range of variation for the decision variable $n$ was

$$
10 \leq n \leq 29 .
$$

4.9. Results of the Application of the Theoretical Model of Nonstationary Queues. As mentioned, a program was developed in Pascal, within a Delphi XE7 platform, in order to apply the model. Table 2 shows the main results obtained with the application of the model, for $n$ ranging from 10 to 29 . The results are referenced to the "box" units (cartons). These values are then divided by $\mu=463,8$ cartons per vehicle to turn them into "vehicles units."

Analyzing Table 2 and Figure 4, the configuration with $n=23$ receiving positions seems satisfactory, with a mean queue of 5.4 vehicles and a mean waiting time of 0.23 hours. We show that an approximate and nonstationary model of the queue, based on a continuous representation of the central variable, can provide sufficient results for a preliminary analysis of the problem. Through a simulation model, the analysis can be deepened, leading to more accurate values of the results.

\section{Simulation}

Simulation is a process of analysis and synthesis, useful as a tool to aid decision making in complex productive processes. Therefore, it is understood as simulation of all the process of elaboration of a computational model representative of a real (or hypothetical) system and the conduction of experiments in order to understand the behavior of a system and/or evaluate strategies for its operation (Shannon [33]). 
TABLE 2: Results of the theoretical model application.

\begin{tabular}{|c|c|c|c|c|c|}
\hline $\begin{array}{l}\text { Number of } \\
\text { positions }\end{array}$ & $\begin{array}{c}\text { Average } \\
\text { queue } \\
\text { (vehicles) }\end{array}$ & $\begin{array}{l}\text { Average wait } \\
\text { time }(\mathrm{h})\end{array}$ & $\begin{array}{c}\text { Average } \\
\text { system time } \\
\text { (h) }\end{array}$ & $\begin{array}{c}\text { Total average } \\
\text { usage time of } \\
\text { docks (h) }\end{array}$ & $\begin{array}{c}\text { Average dock } \\
\text { occupancy } \\
\text { rate }(\%)\end{array}$ \\
\hline 10 & 39.9 & 3.20 & 3.75 & 15.43 & 86.7 \\
\hline 11 & 36.0 & 2.66 & 3.22 & 14.29 & 85.1 \\
\hline 12 & 32.4 & 2.23 & 2.79 & 13.35 & 83.5 \\
\hline 13 & 28.9 & 1.87 & 2.43 & 12.56 & 81.9 \\
\hline 14 & 25.7 & 1.57 & 2.14 & 11.89 & 80.3 \\
\hline 15 & 22.7 & 1.31 & 1.89 & 11.32 & 78.8 \\
\hline 16 & 19.9 & 1.10 & 1.69 & 10.83 & 77.2 \\
\hline 17 & 17.2 & 0.91 & 1.51 & 10.41 & 75.6 \\
\hline 18 & 14.8 & 0.75 & 1.36 & 10.04 & 74.1 \\
\hline 19 & 12.6 & 0.62 & 1.24 & 9.71 & 72.5 \\
\hline 20 & 10.5 & 0.50 & 1.13 & 9.42 & 71.0 \\
\hline 21 & 8.6 & 0.40 & 1.04 & 9.17 & 69.5 \\
\hline 22 & 6.9 & 0.31 & 0.97 & 8.94 & 68.0 \\
\hline 23 & 5.4 & 0.23 & 0.90 & 8.74 & 66.5 \\
\hline 24 & 3.9 & 0.17 & 0.85 & 8.73 & 65.1 \\
\hline 25 & 2.7 & 0.12 & 0.81 & 8.73 & 63.6 \\
\hline 26 & 1.7 & 0.07 & 0.78 & 8.73 & 62.2 \\
\hline 27 & 0.9 & 0.04 & 0.75 & 8.73 & 60.8 \\
\hline 28 & 0.4 & 0.02 & 0.74 & 8.73 & 59.4 \\
\hline 29 & 0.1 & 0.00 & 0.73 & 8.73 & 58.0 \\
\hline
\end{tabular}

Simulation is used when it is not possible to experiment with the real system (due, for example, to the time required to perform the experiment, or to the high cost of the experiment, or to the difficulty of physically carrying the experiment) (Law and Kelton [34]). This is also the great advantage of simulation, allowing real studies of systems without modifying them, with speed and low cost when compared to the real physical and organizational changes necessary to study the same alternatives of future scenarios. In this way, changes can be tried and studied in a systematic way without interfering with the real system (Baker [35]).

Now by using the simulation it would be viable and practical to check (i) in what level of precision the theoretical model approaches the actual models; (ii) if the issue (i) is not verified, what adjustments are needed to make the theoretical model so that it fits the real problems; (iii) simulation utilizing tools for the problem to be as much detailed as possible, which is not allowed in the theoretical model.

5.1. Modeling and Simulating Model Using ARENA. The package chosen for the simulation process is the modeling process using the Arena Simulator and the model is structured and coded based on the SIMAN simulation language through the selection of modules that contain the characteristics of the processes to be modeled.

When working with simulation, it is initially necessary to define how long the simulation will run (one day, one week, one month, or only a few hours). Normally, this definition is made according to the very nature of the system being modeled.

Finally, another extremely important parameter is how many replications/rounds or samples of the simulation will be made. As in the simulation random variables are provided using probability distributions, running the simulation for just one day does not mean that on that day we will have a "typical" day.

Figure 5 shows a sketch containing the main parts of the simulated model, where

(i) the process of arrival of the trucks in the model starts with the creation of the entity (truck) that arrives at the Distribution Center. In order to simulate the arrivals of the trucks, according to the same criterion used in the theoretical model, a program was developed using the Pascal programming language, where the function that generates the delivery distribution curve of the trucks of Figure 2 was implemented. With each new replication a new distribution curve is simulated for the arrival of the trucks;

(ii) reading this entry, the truck undergoes a management of the queue; that is, when arriving at the reception the entity is referred directly to the attendance at the reception docks. If all the docks are occupied the entity enters a waiting queue on the patio; as soon as a dock is free the first waiting truck comes in to be taken care of. It is not in the interest of this study to find the best unloading dock door for inbound trucks 


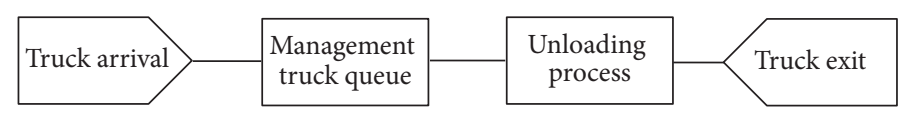

FIGURE 5: Sketch of the simulated model.

in order to minimize the distances within the $\mathrm{CD}$ for the outgoing trucks;

(iii) the unloading of the trucks obeys the same distribution of the theoretical model. In the first phase of the simulation, the average service time shown in Table 1 was considered, with discharge times governed by log-normal distribution, with mean $\bar{S}=43,8 \mathrm{~min}$ and standard deviation $\sigma_{S}=12,8 \mathrm{~min}$. In fact, the simplified stochastic model described in the previous sections does not allow distinction of vehicle types, and as one wishes to compare the results of the two approaches, an average equivalent type of vehicle is initially allowed;

(iv) after unloading, the truck is routed to the system exit.

The resources used vary according to the theoretical model previously seen, from 10 to 29 ports.

\subsection{Simulation Results Analysis Compared to the Theoretical} Model. The analysis process of the simulation results performed through the computational model deals with the data that were obtained from the experiments. The main objective is to allow the realization of inferences and predictions about the behavior and performance of the created simulation model. The main reason for a greater attention to the processes of analysis of the results of the simulations is based on the fact that, in general, the models present a stochastic behavior similar to the systems they are imitating (Freitas and Paulo [36]).

The verification and validation processes of the model are developed considering the results of the executions carried out in the simulation model. The results of the simulation can be presented in a number of ways. Harrel and Tumay [37] commented that there are several types of simulation reports; among them the author cites analysis of multiple replication reports that provide combined results of several rounds of simulation, making statistical treatments in the results with estimates of errors, within a desired uncertainty range, based on the Output Analyzer.

The analysis of the results also depends on the type of simulation adopted. The simulation can be identified as terminal or nonterminal. The difference between the two lies in the possibility of defining a length for the simulation. If a system has clearly defined a start time and an end time, the system is considered terminal. Otherwise, it is called the nonterminal system. In our case the treated system is terminal. For the terminal simulation it is important to establish how many runs (replications) must take place in order for the statistical results to be consistent (Freitas and Paulo [36]).

To be treated it was a terminal system, the chosen form of output analysis was through multiple replications, analyzing

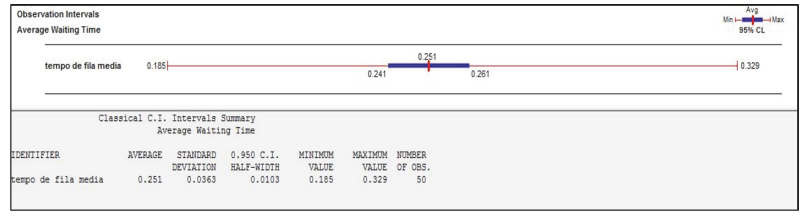

FIgURE 6: Result of the analysis of the Output Analyzer.

the deviations, under an uncertainty rate, with the results being treated through confidence intervals.

As in the theoretical model, the confidence level was assumed to be $95 \%$; that is, $a=5 \%=0.05$. We considered 23 docks for the tests that determine the number of replications. With the aid of the Arena Output Analyzer tool and following the method applied by Freitas and Paulo [36], a number of 50 replications were obtained (Figure 6), which was adequate to the problem studied, with an overall average waiting time of 0.25 , standard deviation of 0.04 , and semiconfidence interval of 0.01. According to Freitas and Paulo [36] it is common to find confidence intervals for which the value of $h$ is approximately less than or equal to $10 \%$ of the sample mean.

For the analysis of the results obtained with the application of the simulation model, the same variation of the number of doors of the theoretical model was used, from 10 to 29 docks. Table 3 shows the mean of the results obtained with 50 replications.

Looking at Figure 7 it is clear that the curves are coincident in almost all points. Two behavioral ranges are observed in the curves, when $n \geq 23$ the variation in waiting time tends to be linear, whereas for $n<23$ the variation is exponential, as in the theoretical model presented. The mean waiting time in the theoretical was $0.23 \mathrm{~h}$, in the simulation it reached $0.24 \mathrm{~h}$, that is, 14.4 minutes. The average queue is 5.4 vehicles in the theoretical model; in the simulated model this number is practically the same as 4.9 vehicles.

Another important factor for analysis of the solution is the average occupation rate of the docks. In Figure 8, the curves of the mean time and total time in the system as a function of the average occupancy rate provide a curve that closely resembles graph 6 of the theoretical model; the curve has an exponential behavior at the beginning tending to linearity as the number of doors increases. It does not make any difference to have more doors to receive loads, because their occupancy rate reaches almost $50 \%$ of the total capacity. The total average total time of use of the docks shows that, after the closing of the time window of 8 hours for vehicle reception, the terminal remains in operation for another 1 hour and 6 minutes servicing trucks that still have to be unloaded. Therefore, the previously proposed solution of 23 ports is a possible solution for the case studied. 
TABLE 3: Results of the simulated model application.

\begin{tabular}{|c|c|c|c|c|c|}
\hline $\begin{array}{l}\text { Number of } \\
\text { positions }\end{array}$ & $\begin{array}{c}\text { Average } \\
\text { queue length } \\
\text { (vehicles) }\end{array}$ & $\begin{array}{c}\text { Average } \\
\text { waiting time } \\
\text { (h) }\end{array}$ & $\begin{array}{c}\text { Average } \\
\text { system time } \\
\text { (h) }\end{array}$ & $\begin{array}{l}\text { Total average } \\
\text { usage time of } \\
\text { docks (h) }\end{array}$ & $\begin{array}{c}\text { Average dock } \\
\text { occupancy } \\
\text { rate }(\%)\end{array}$ \\
\hline 10 & 37.4 & 3.18 & 3.99 & 15.63 & 85.7 \\
\hline 11 & 33.6 & 2.65 & 3.41 & 14.47 & 84.1 \\
\hline 12 & 30.4 & 2.25 & 3.01 & 13.60 & 82.1 \\
\hline 13 & 26.9 & 1.87 & 2.61 & 12.78 & 80.6 \\
\hline 14 & 24.1 & 1.59 & 2.32 & 12.17 & 78.7 \\
\hline 15 & 20.6 & 1.35 & 2.09 & 11.57 & 77.2 \\
\hline 16 & 18.2 & 1.10 & 1.86 & 11.10 & 75.4 \\
\hline 17 & 16.0 & 0.93 & 1.63 & 10.63 & 74.1 \\
\hline 18 & 14.1 & 0.80 & 1.52 & 10.32 & 72.1 \\
\hline 19 & 11.5 & 0.63 & 1.39 & 10.01 & 70.4 \\
\hline 20 & 10.2 & 0.55 & 1.25 & 9.68 & 69.2 \\
\hline 21 & 8.30 & 0.43 & 1.16 & 9.24 & 69.0 \\
\hline 22 & 6.80 & 0.35 & 1.06 & 9.24 & 65.9 \\
\hline 23 & 4.90 & 0.25 & 1.00 & 9.10 & 64.0 \\
\hline 24 & 3.40 & 0.21 & 0.94 & 8.95 & 62.4 \\
\hline 25 & 2.98 & 0.14 & 0.87 & 8.77 & 61.1 \\
\hline 26 & 2.23 & 0.11 & 0.83 & 8.77 & 58.7 \\
\hline 27 & 1.55 & 0.08 & 0.81 & 8.75 & 56.7 \\
\hline 28 & 0.90 & 0.05 & 0.78 & 8.73 & 54.8 \\
\hline 29 & 0.30 & 0.03 & 0.76 & 8.73 & 52.9 \\
\hline
\end{tabular}

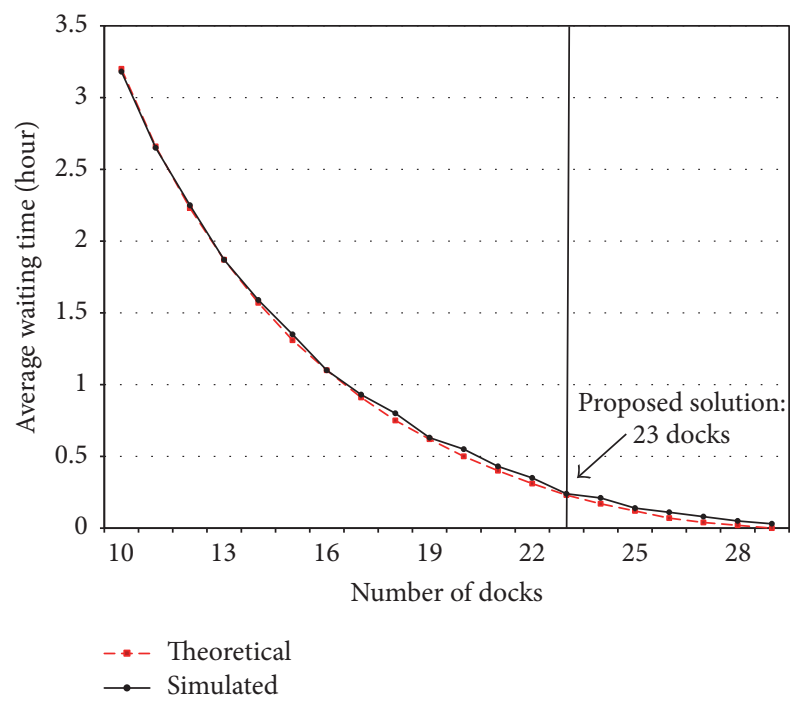

FIgURE 7: Average waiting time in queue.

\section{Conclusions and Future Research}

The basic motivation of this study has been the necessity to analyze the queues generated at the unloading of products that arrive at a cross-dock terminal, a methodology not encountered so far in the literature. In fact, the vehicles must remain the minimum possible time at the terminal, only the time needed to be unloaded, letting their cargo to be internally transferred to the trucks that will deliver the cargo

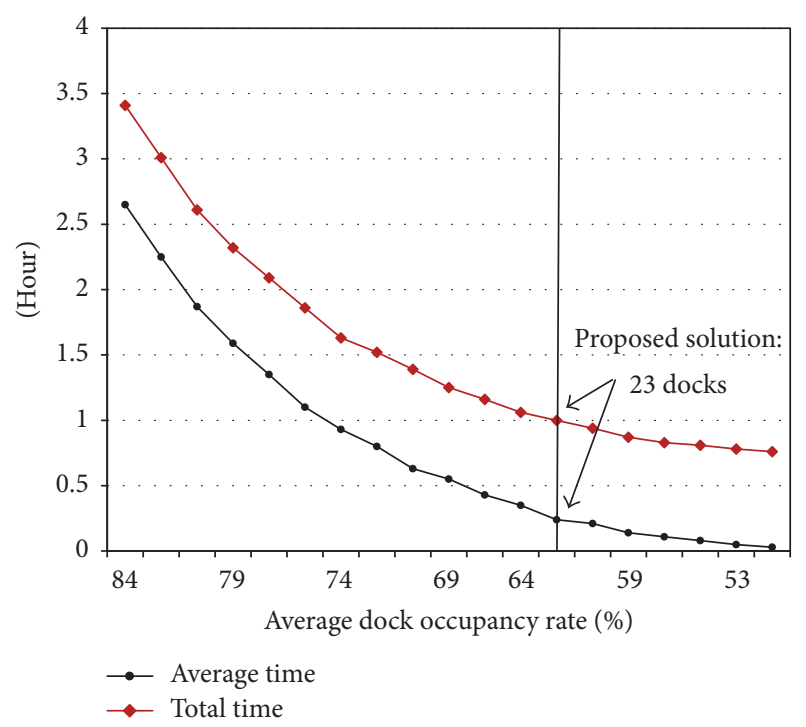

FIGURE 8: Average waiting time and total waiting time.

to the final destinations. To this respect, the employment of simulation modeling in the present work allowed for more realistic analysis of a cross-dock terminal operation. Specifically, it permitted defining a number of dock doors more compatible with the quantity of trucks received per day at the terminal, thereby reducing the congestion observed when unloading incoming vehicles, and consequently inducing a reduction of operating costs. 
Through the simulation model we studied a specific application of the methodology to a cross-docking terminal of a supermarket chain. We obtained very similar results when applying a theoretical queuing model formulation, compared to the simulation analysis results. The advantage of employing a theoretical framework is the ease of computing via explicit mathematical formulas and numerical computation techniques. On the other hand, the use of simulation opens to the analyst a plethora of representation possibilities, allowing for a more detailed simulation approach level. Another simulation advantage is that it can detect possible bottlenecks in the system and produce graphical representations which are very handy in the discussion of system drawbacks and possible corrections.

It remains a need for more research investigation on this sector of logistics supply chain problems, namely, cross-dock design and operation. An associated problem to be tackled by researchers is the internal displacement of cargo units from the discharging doors to the areas allocated to shipping trucks. The assignment of trucks to doors in such a way as to minimize internal carrying costs might lead to substantial operational savings.

Finally, although it has been not easy to apply such modeling tools to real cases in developing countries like Brazil, due to empirical approaches and proprietary restrictions, the search for possible practical applications will be explored further. Presentation of such methodology possibilities at technical and academic conferences, many of them attended by transportation and logistics professionals, is a likely promising alternative.

\section{Conflicts of Interest}

The authors declare that there are no conflicts of interest regarding the publication of this paper.

\section{References}

[1] J. Van Belle, P. Valckenaers, and D. Cattrysse, "Cross-docking: State of the art.," Omega-International Journal of Management Science, vol. 40, no. 6, pp. 827-846, 2012.

[2] S. B. Schaffer, "Cross-docking can Increase Efficiency," Automatic ID News, vol. 14, no. 8, pp. 34-37, 1998.

[3] N. Boysen and M. Fliedner, "Cross dock scheduling: Classification, literature review and research agenda," Omega, vol. 38, no. 6, pp. 413-422, 2010.

[4] P. Buijs, I. F. A. Vis, and H. J. Carlo, "Synchronization in crossdocking networks: a research classification and framework," European Journal of Operational Research, vol. 239, no. 3, pp. 593-608, 2014.

[5] D. Agustina, C. K. M. Lee, and R. Piplani, "A review: mathematical modles for cross docking planning," International Journal of Engineering Business Management, vol. 2, no. 2, pp. 47-54, 2010.

[6] S. M. Mousavi and R. T. Moghaddam, "A hybrid simulated annealing algorithm for location and routing scheduling problems with cross-docking in the supply chain," Journal of Manufacturing Systems, vol. 32, no. 2, pp. 335-347, 2013.

[7] K. K. Yang, J. Balakrishnan, and C. H. Cheng, "An analysis of factors affecting cross docking operations," Journal of Business Logistics, vol. 31, no. 1, pp. 121-148, 2010.
[8] I. F. A. Vis and K. J. Roodbergen, "Layout and control policies for cross docking operations," Computers and Industrial Engineering, vol. 61, no. 4, pp. 911-919, 2011.

[9] J. J. Bartholdi III and K. R. Gue, "The best shape for a crossdock," Transportation Science, vol. 38, no. 2, pp. 235-244, 2004.

[10] C.-J. Liao, Y. Lin, and S. C. Shih, "Vehicle routing with crossdocking in the supply chain," Expert Systems with Applications, vol. 37, no. 10, pp. 6868-6873, 2010.

[11] J. Gonzalez-Feliu, "Cost optimisation in freight distribution with cross-docking: N-echelon location routing problem," Promet - Traffic - Traffico, vol. 24, no. 2, pp. 143-149, 2012.

[12] G. Dobrusky Fernando, Optimal Location of Cross-docking Centers for a Distribution Network in Argentina, Industry Engineering: Columbia University, 2003.

[13] Y. H. Lee, J. W. Jung, and K. M. Lee, "Vehicle routing scheduling for cross-docking in the supply chain," Computers \& Industrial Engineering, vol. 51, no. 2, pp. 247-256, 2006.

[14] L. Y. Tsui and C.-H. Chang, "An optimal solution to a dock door assignment problem," Computers and Industrial Engineering, vol. 23, no. 1-4, pp. 283-286, 1992.

[15] J. J. Bartholdi III and K. R. Gue, "Reducing labor costs in an LTL crossdocking terminal," Operations Research, vol. 48, no. 6, pp. 823-832, 2000.

[16] R. Soltani and S. J. Sadjadi, "Scheduling trucks in cross-docking systems: a robust meta-heuristics approach," Transportation Research Part E: Logistics and Transportation Review, vol. 46, no. 5, pp. 650-666, 2010.

[17] M. Shakeri, M. Y. H. Low, S. J. Turner, and E. W. Lee, "A robust two-phase heuristic algorithm for the truck scheduling problem in a resource-constrained crossdock," Computers and Operations Research, vol. 39, no. 11, pp. 2564-2577, 2012.

[18] N. Goddefroy and M. Alexandrer, Optimizing the dock door assignment problem in Cross-docking warehouses, Universiteit Gent Faculteit Economie En Bedrijfskunde, 2013.

[19] D. Konur and M. M. Golias, "Analysis of different approaches to cross-dock truck scheduling with truck arrival time uncertainty," Computers and Industrial Engineering, vol. 65, no. 4, pp. 663-672, 2013.

[20] M. Rohrer, "Simulation and cross docking," in Proceedings of the 1995 Winter Simulation Conference, WSC'95, pp. 846-849, December 1995.

[21] K. R. Gue and K. Kang, "Staging queues in material handling and transportation systems," in Proceedings of the 2001 Winter Simulation Conference, pp. 1104-1108, December 2001.

[22] G. D. Taylor and J. S. Noble, "Determination of Staging Needs in a Crossdock Environment," in Proceeding of 2004 Industrial Engineering Research Conference, 2004.

[23] S. Sandal, Staging Approaches to Reduce Overall Cost in a Crossdocking Environment. Thesis presented to the Faculty of the Graduate School, University of Missouri, Columbia, Mo, USA, 2005.

[24] P. Chen, Y. Guo, A. Lim, and B. Rodrigues, "Multiple crossdocks with inventory and time Windows," Computer Operations Research, vol. 33, no. 1, pp. 43-63, 2006.

[25] G. Arnaout, E. Rodriguez-Velasquez, G. Rabadi, and R. Musa, Cross-docking Operations Using Discrete Event Simulation, Hammamet, Tunisia, 2010.

[26] A. M. M. Ferreira, Métodos para geração de entidades, em modelos de simulação, para processos estocásticos de renovação não-estacionários [Doctors Engineering Thesis], UFPR, Paraná, Brazil, 2009, (in Portuguese). 
[27] F. Schwind Gene, "A Systems Approach to Docks and Crossdocking," Material Handling Engineering, vol. 51, no. 2, pp. 5962, 1996.

[28] A. R. Odoni and R. de Neufville, "Passenger terminal design," Transportation Research Part A, vol. 26, no. 1, pp. 27-35, 1992.

[29] G. F. Newell, "Queues with time-dependent arrival rates. I. The transition through saturation," Journal of Applied Probability, vol. 5, pp. 436-451, 1968.

[30] G. F. Newell, Applications of Queuing Theory, Chapman and Hall, London, UK, 1971.

[31] G. N. Novaes Antônio, Métodos de Otimização: Aplicações aos transportes, Edgard Blucher, São Paulo, Brazil, 1978, (in Portuguese).

[32] J. D. Little and S. C. Graves, "Little's law," in Building Intuition, D. Chhajed and T. J. Lowe, Eds., vol. 115 of International Series in Operations Research \& Management Science, pp. 81-100, Springer US, Boston, Mass, USA, 2008.

[33] R. E. Shannon, Systems Simulation: The Art and Science, Upper Saddle River, NJ, USA, Prentice-Hall, 1975.

[34] A. M. Law and W. D. Kelton, Simulation Modeling and Analysis, McGraw-Hill, 3rd edition, 2000.

[35] J. F. Baker, Evaluation of Genotype-Environment Interactions in Beef Cattle Production Systems Using A Computer Simulation Model, Texas A \& M University, College Station, Tex, USA, 1982.

[36] F. Freitas and J. Paulo, Introdução a modelagem e simulação de sistemas com aplicações em Arena, Visual Books, Florianópolis, SC, Brazil, 2008, (in Portuguese).

[37] C. H. Harrel and K. Tumay, Simulation Made Easy: A Manager's Guide. Engineering and Norcross, Management Press, Engineering and Norcross, 1995. 


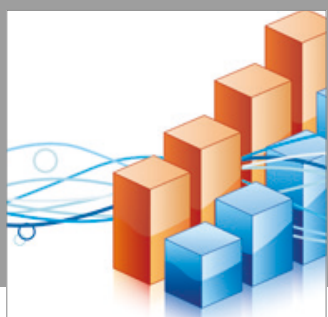

Advances in

Operations Research

vatersals

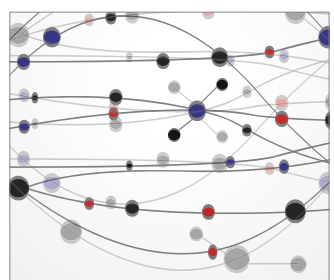

\section{The Scientific} World Journal
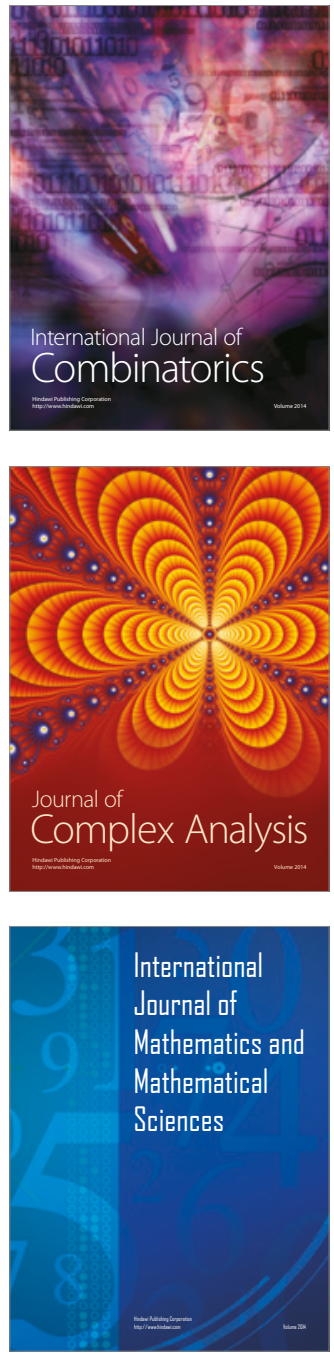
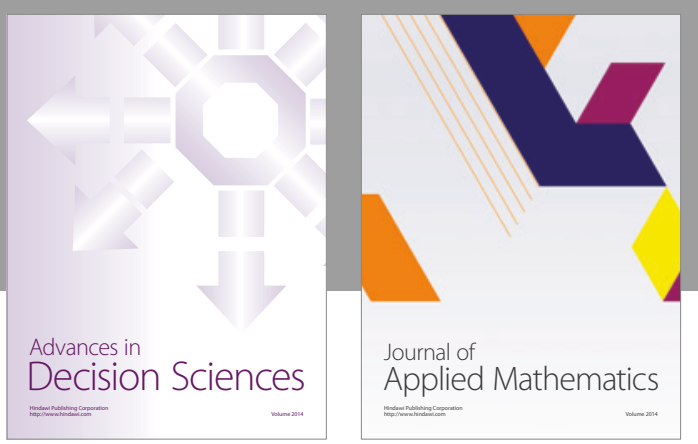

Algebra

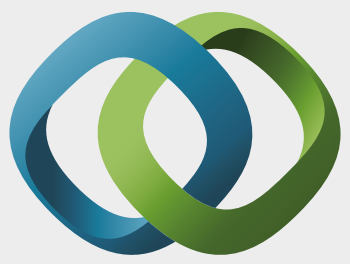

\section{Hindawi}

Submit your manuscripts at

https://www.hindawi.com
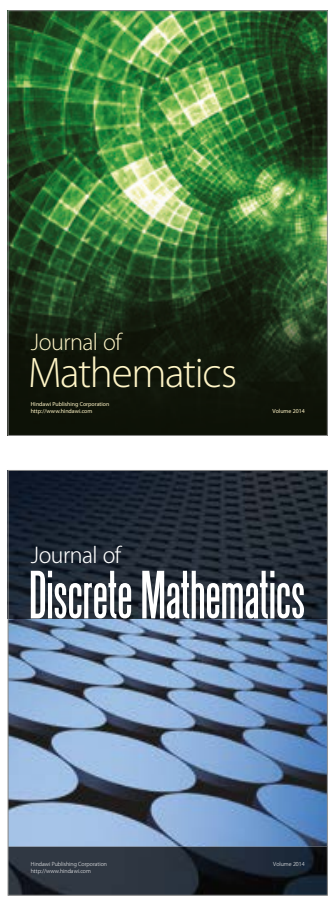

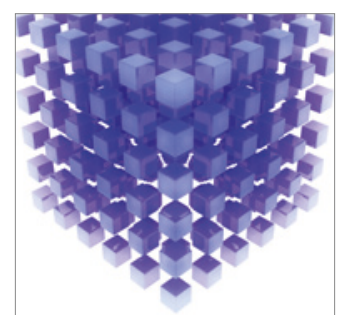

Mathematical Problems in Engineering
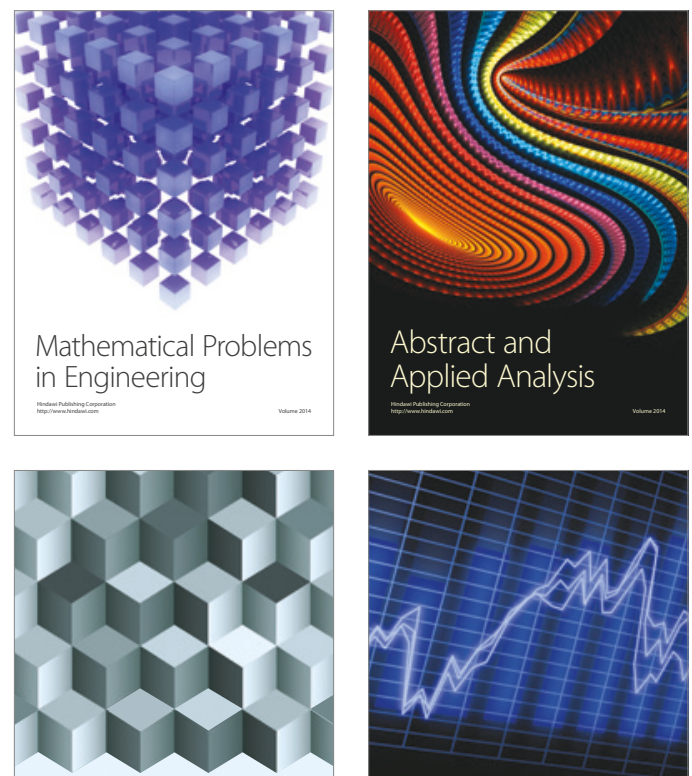

Journal of

Function Spaces

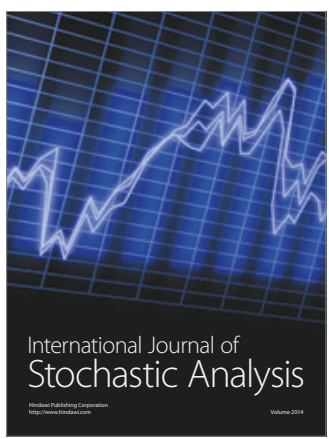

Probability and Statistics
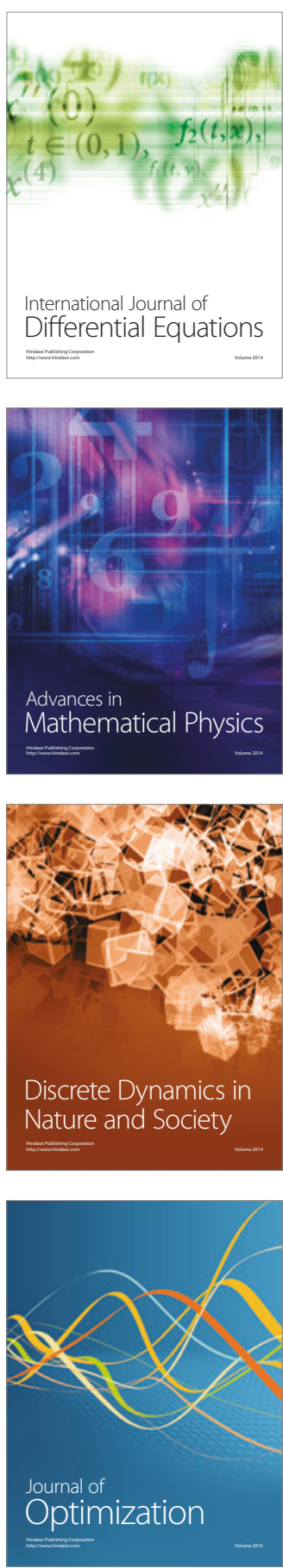